\title{
Nickel and tattoos: Where are we?
}

\author{
Nicolas Kluger ${ }^{1,2}$ ৫
}

${ }^{1}$ Department of Dermatology, Allergology and Venereology, Helsinki University Hospital \& University of Helsinki, Helsinki, Finland

2,"Tattoo" Consultation, Department of Dermatology, Bichat-Claude Bernard Hospital, Assistance Publique - Hôpitaux de Paris, Paris, France

\section{Correspondence}

Adj. Prof. Nicolas Kluger, Department of Dermatology, Skin and Allergies Hospital, Helsinki University Hospital, Meilahdentie 2, PO Box 160, 00029 Helsinki, Finland. Email: nicolas.kluger@hus.fi

\begin{abstract}
Tattoos are not mentioned as a source of exposure to nickel. Traces of nickel are, however, almost inevitably found in tattoo inks as impurities and sometimes in tattooed skin. Whether nickel in tattoos has any health consequence is debated. We performed a narrative review of what is currently known about this topic. Today, nickel is frequently detected in inks, but at highly variable levels. It appears to be at higher concentrations in green, blue, and sometimes brown and violet inks. Only nickel allergy in tattooed individuals and nickel-associated tattoo ink allergy are addressed in the literature. Reports of tattoo ink allergy related to nickel are rare and heterogenous. Authors often neglect possible implications of other metals or dyes. A positive patch test is not enough to confirm the role of nickel in a reaction observed after tattooing. We found no report of any systemic complication attributed to nickel from tattoos. The Council of Europe $\operatorname{ResAP(2008)1~bans~the~presence~of~nickel~at~}$ high levels in tattoo inks, which is a safety net for individuals with nickel allergy. Large epidemiologic case-control studies with systematic biopsies on normal and inflamed tattoos and patch testing would help to understand the role of nickel in tattoo ink allergies.
\end{abstract}

\section{KEYWORDS}

ink, nickel, tattoo, tattoo allergy, tattooing
Tattoos are exceedingly popular, as approximately $18 \%$ of the adults worldwide have at least one tattoo. ${ }^{1}$ Allergic reaction to tattoo ink (or "tattoo ink allergy") is the most common complication that is encountered in specialized consultations. ${ }^{2-4}$ There is no international definition for an allergic tattoo reaction. We previously defined it as (i) a chronic and constant reaction; (ii) restricted to one or more tattoos; (iii) limited to one colour; (iv) occurring within a variable timeframe, from immediately after tattooing to many years later; (v) clinically characterized by a swelling affecting a part of this colour or its totality, realizing a permanent diffuse infiltration; (vi) often associated with pruritus and more rarely with pain. ${ }^{5}$ Ink allergy develops mostly against red shades. ${ }^{6}$ It is challenging to treat, with a protracted evolution and a non-negligible impact on quality of life due to local itch or pain. ${ }^{7}$ Tattoo inks are a complex mixture of pigments or dyes, metallic salts, and various additives ${ }^{8}$ and thus precisely identifying the culprit seems unlikely. Ink allergy is not a contact allergy stricto sensu as the culprit allergen is in the dermis. Contact dermatitis after tattooing is usually caused by aftercare products. Nickel is the most common cause of contact allergy and is responsible for allergy in $8 \%$ to $19 \%$ of adults worldwide. ${ }^{9,10}$ It is used in a variety of products. Sources of exposure are metallic items such as piercings, household products, cosmetics, and implants. ${ }^{9}$ We performed a narrative review of the current knowledge on the presence of nickel in tattoos. References for this review were found through a PubMed search using the terms "tattoo or tattoos or tattooing" AND "nickel" with no time restriction. This review will not discuss specifically other metals in tattoos.

This is an open access article under the terms of the Creative Commons Attribution-NonCommercial-NoDerivs License, which permits use and distribution in any medium, provided the original work is properly cited, the use is non-commercial and no modifications or adaptations are made.

(c) 2021 The Author. Contact Dermatitis published by John Wiley \& Sons Ltd. 


\section{1 | PREVALENCE OF NICKEL ALLERGY IN TATTOOED INDIVIDUALS}

Very few data are available regarding the prevalence of nickel allergy among tattooed individuals. Fors et $\mathrm{al}^{11}$ evaluated the prevalence of patch-tested nickel allergy in 4376 Swedish pupils (aged 15-23 years) and compared the results with lifestyle behaviours, including tattooing. Five percent of the participants had tattoos ( $6 \%$ of the girls and $3 \%$ of the boys). Tattooed boys had a threefold and girls a twofold increased risk of nickel allergy compared with non-tattooed peers. However, multivariate analysis failed to demonstrate an association with tattooing. Piercing increased the risk of allergy and pierced individuals tended to have tattoos. ${ }^{11}$ In a more recent Swedish study among 3115 adolescents aged $16,2.4 \%(n=71)$ had tattoos. ${ }^{12}$ Tattoos were significantly more common among the nickel-positive adolescents (4.2\%) compared with nickel-negative adolescents (1.7\%) Self-reported tattooing was associated with an increased odds ratio of contact allergy to nickel (adjusted odds ratio 2.34, 95\% confidence interval 1.02-5.39). ${ }^{12}$ However, the authors did perform statistical adjustment only for gender, but not for piercing. Piercing is a major factor in this regard, as $83 \%(n=59)$ of the tattooed adolescents had piercings and piercing is strongly associated with nickel allergy. ${ }^{12}$

\section{2 | NICKEL IN TATTOO INK SAMPLES}

Among 11 studies analysing samples of tattoo inks, ${ }^{13-23}$ many failed to report nickel. ${ }^{13-15,17,19}$ Forte et $\mathrm{al}^{20}$ were the first to find nickel in a large survey of 56 inks from four different brands. Nickel concentration ranged from 0.037 to $9.59 \mu \mathrm{g} / \mathrm{g}$ and exceeded the safe allergological limit (at the time of the study) of $1 \mu \mathrm{g} / \mathrm{g}$ in $16 \%$ of cases (nine inks; all four brands had a least one ink above the permissible range). Colours that tended to have the highest amount were blue, green, violet, and brown. Red hardly reached the safe limit. ${ }^{20}$ Cristaudo et al $^{21}$ analysed seven tattoo inks collected from tattoo shops (four colours: black, blue, red, and violet). Nickel was detected in all samples $(0.10-9.50 \mu \mathrm{g} / \mathrm{g})$, but the highest concentrations were found in black and blue colours $(2.1-9.50 \mu \mathrm{g} / \mathrm{g})$.

Corazza et $\mathrm{al}^{16}$ were the first to find nickel in a red ink. Graphite furnace atomic absorption spectroscopy demonstrated the presence of nickel at $1.90 \mu \mathrm{g} / \mathrm{g}$ in the ink. In their study, the patient had a lichenoid red tattoo reaction a few weeks after tattoo completion. Patch tests showed a strong reaction to nickel and to the original "cardinal red" pigment, but not to mercury. The authors concluded on a possible role of nickel. However, the authors did not provide information about the levels of other elements in the ink. Cardinal red was indeed expected to contain cinnabar (mercury sulfide). ${ }^{16}$ Jäger and Jappe $^{18}$ reported the case of a 52-year-old-woman who developed a reaction 3 days after permanent make-up of the lips. Patch tests were strongly positive for nickel sulfate $(+++$ at $72 \mathrm{~h}$ ) and mildly positive for the lip liner ( + at $72 \mathrm{~h}$ ). Nickel was found at the concentration of $1.8 \mu \mathrm{g} / \mathrm{g}$. The detection of other elements by mass spectrometry was again omitted.

\section{3 | NICKEL IN TATTOOED SKIN SAMPLES}

We found only seven publications, in which the authors used tattooed skin samples to investigate the presence nickel in tattoo inks. $^{13,21,23-27}$

Serup et $\mathrm{al}^{23}$ performed the largest analysis with a series of 104 skin biopsies from 104 patients with an allergic reaction to a red tattoo. More than $67 \%(n=70)$ of the samples contained nickel at a mean concentration of $1.05 \mu \mathrm{g} / \mathrm{g}$, among which $54 \%$ of the samples contained nickel above the maximum control values. ${ }^{16}$ MoralesCallaghan et $\mathrm{al}^{25}$ identified iron at $13 \%$, cobalt $(12 \mu \mathrm{g} / \mathrm{g})$, nickel $(11 \mu \mathrm{g} / \mathrm{g})$, and zinc $(100 \mu \mathrm{g} / \mathrm{g})$ in the biopsy of a skin with granulomatous reaction that developed within the black part of a 10-month-old tattoo in a 23-year-old woman. Patch tests displayed positive reaction to nickel, cobalt, and cadmium. Cristaudo et $\mathrm{al}^{21}$ analysed skin biopsies of three patients with pseudolymphoma in the red part of tattoos. Eruption appeared between 12 and 18 months after tattooing in two patients. Nickel was found in all samples at concentrations from 0.84 to $2.48 \mu \mathrm{g} / \mathrm{g}$. Other metals detected were cadmium, cobalt, chromium, mercury, and lead. Patch tests were negative for all patients. The authors reported that they collected the inks used at the shops; however, because there was delayed onset ( $>1$ year) after tattooing, it is unlikely they analysed the culprit vials (Table 1). ${ }^{21}$ Schreiver et $\mathrm{al}^{26}$ analysed four samples of tattooed human skin from anonymous deceased individuals. None of the individuals were reported to have had an allergic reaction from their tattoos. However, nickel was found at different levels in the biopsy specimens, although their medical history, habitus, and occupational exposure were unknown. ${ }^{26}$ van der Bent et $\mathrm{al}^{27}$ presented a case of a 40-year-old woman who developed an itchy reaction against green colour within a 10-year-old tattoo. Her reaction developed 6 years after tattooing. Patch testing was positive for nickel sulfate $(++)$ at $72 \mathrm{~h}$, as well as for methyldibromo glutaronitrile $(++)$, palladium $(+++)$, and cadmium $(+)$. Micro-X-ray fluorescence analysis and laser ablation-inductively coupled plasma mass spectrometry revealed the presence of chlorine, titanium, chromium, iron, nickel, copper, zirconium, and niobium in the tattoo. The concentration of nickel ranged from less than 7 to over $30 \mu \mathrm{g} / \mathrm{g}$. The overall mean concentration in the skin sample was, however, not provided. ${ }^{27}$

\section{4 | PREVALENCE OF NICKEL ALLERGY IN PATIENTS WITH AN ALLERGIC TATTOO REACTION}

A study of allergy patch testing in 90 patients with chronic tattoo reactions, also including allergy in red tattoos, showed positive reaction to nickel sulfate in $21 \%$ of the cases. All of those in the nickel patch test-positive group were sensitized before the tattooing. ${ }^{28}$ In a second series from the same group of patients $(n=104)$ with allergic reactions in red tattoos, $27 \%$ stated that they had metal allergy. ${ }^{23}$ In a retrospective review by the North American Contact Dermatitis Group from 2001 to 2016, 29 individuals were patch tested for tattoo-related allergic contact dermatitis. The group found only one 
TABLE 1 Detection of nickel in inks and tattooed skin

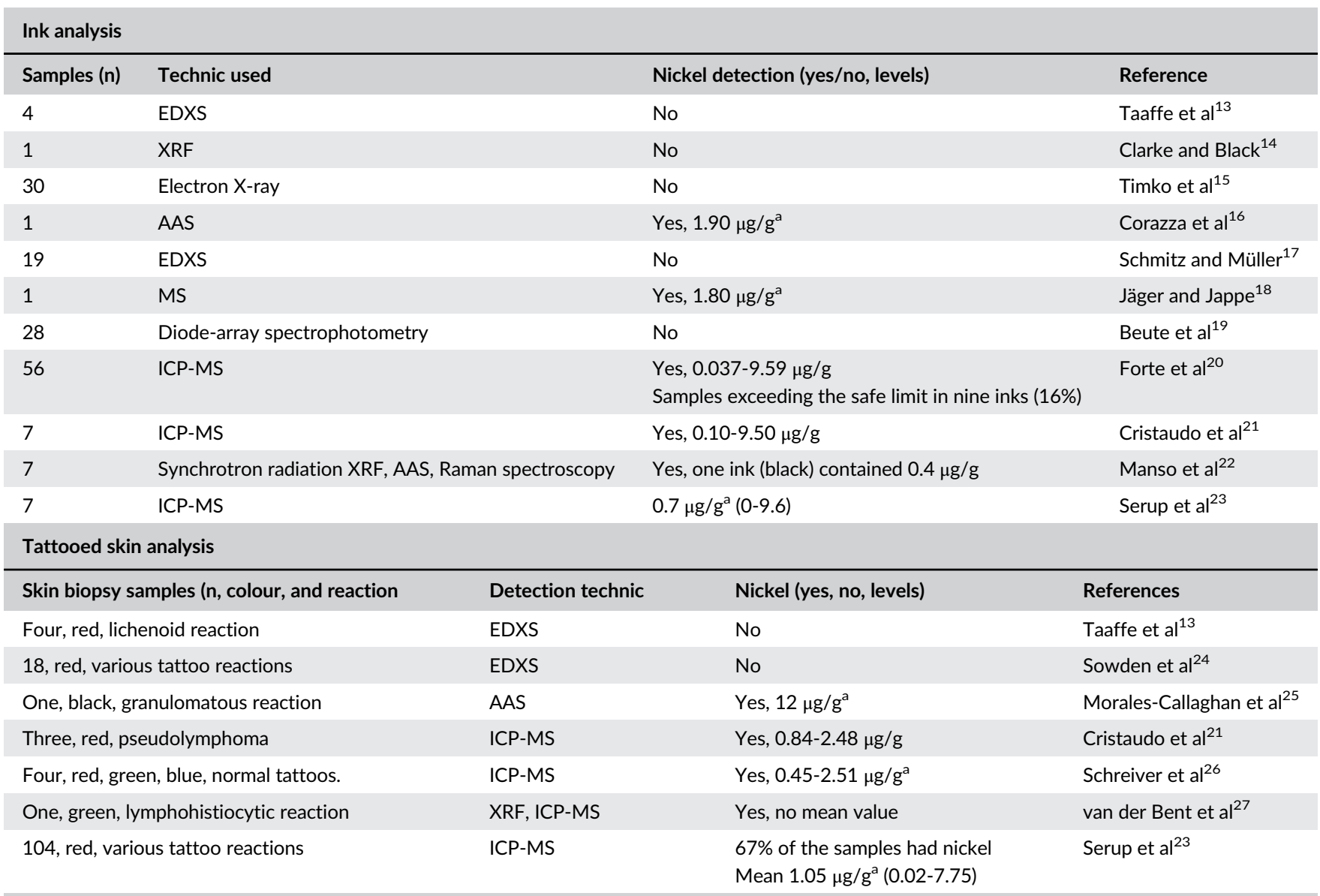

Abbreviations: AAS, atomic absorption spectroscopy; EDXS, energy-dispersive X-ray spectroscopy; ICP-MS, inductively coupled plasma mass spectrometry; MS, mass spectrometry; XRF, X-ray fluorescence.

${ }^{a}$ Data in the articles provided as ppm.

individual (4\%) with nickel allergy. However, the study is limited by the lack of distinction between temporary and permanent tattoos. ${ }^{29}$ In a series of six patients with reactions in red tattoos, two had positive patch test results to nickel. ${ }^{30}$

\section{5 | NEEDLES AS ANOTHER SOURCE OF NICKEL?}

Schreiver et $\mathrm{al}^{31}$ found that as a result of wearing of the tattoo needle, which is composed of iron, $6 \%$ to $8 \%$ nickel, and $15 \%$ to $20 \%$ chromium, it is possible that the aforesaid elements could be deposited in the skin in the presence of titanium dioxide in the ink used for tattooing. However, this is a unique small study and nickel was found in the skin as well as in draining lymph nodes. Of interest, they also found in a patient with an allergic skin reaction to a tattoo that the high concentration of nickel in the tattooed skin is due to a possible wear of the steel in the tattoo needle. ${ }^{31}$ Therefore, metals found in tattooed skin samples may have various origins (tattoo inks, needle wear, or other environmental factors).

\section{6 | INTERPRETATION AND LIMITATIONS}

Nickel is definitely present in tattoo inks and tattooed skin samples. It mainly originates from impurities in pigments, mainly iron oxides, ${ }^{31,32}$ but also possibly from needle wear and other individual-based environmental factors. $^{23}$ Nickel concentrations are highly variable between brands and colours. Therefore, detection of nickel in inks or tattooed skin sample should not come as a surprise and caution is warranted regarding interpretation. The likelihood of a fortuitous discovery of nickel allergy in tattooed individuals during patch testing is high. $^{28}$

To date, there is no evidence that tattooing is an independent risk factor for nickel allergy. Piercing is a major cofounding factor, ${ }^{11,12}$ and other environment factors need to be considered, such as occupations ${ }^{9}$ or smoking, for instance. Indeed, smoking is prevalent among tattooed individuals ${ }^{33}$ and is associated with nickel sensitization. ${ }^{34}$

Evidence that nickel could be implicated in tattoo reactions are very limited. The few detailed clinical reports about tattoo reactions and nickel allergy are heterogenous: lichenoid reaction to red, ${ }^{16}$ pseudolymphoma to red, ${ }^{21}$ granulomatous reaction to black, ${ }^{25}$ lymphohistiocytic reaction to green. ${ }^{27}$ Authors usually speculate on 
the role of nickel based on patch tests and detection of nickel in the ink or in the skin, with the aforesaid stressed limitations. The possible role of other metals such as mercury ${ }^{16}$ or azo or other dyes ${ }^{23,28,30}$ is usually neglected. Besides, green and blue, sometimes brown and violet are the colours that contain the highest concentration of nickel in the reviewed studies. This is important as large studies have focused on red tattoo reactions. ${ }^{23}$

Nickel allergy could play a role in already sensitized individuals, as it tends to cause elicitation reactions in new tattoos during the first few days after tattooing, as suggested by Serup et al. ${ }^{28}$ For instance, the case reported by Jäger and Jappe ${ }^{18}$ (ie, a reaction due to permanent make-up of the lips within a few days of application in a woman with nickel allergy) fits this hypothesis. ${ }^{18}$ By contrast, allergy to nickel is unlikely to explain delayed reaction months to years after tattooing. ${ }^{23,28}$

There is a gap in knowledge on the amounts of tolerable nickel injected intradermally and the risk of elicitation. Nickel-soluble ions are responsible for nickel allergy. ${ }^{9,23}$ In tattoo inks, iron oxides are one of the main sources of nickel as an impurity. However, nickel in iron oxides is not soluble in water, and therefore its bioavailability should be limited and its implication in allergy reaction is unlikely. ${ }^{32}$ According to the Resolution ResAP(2008)1 of the Council of Europe, ${ }^{35}$ maximum levels of nickel should be "as low as technically achievable." The lack of analytical methods and of clear threshold leave room for interpretation by the authorities. ${ }^{32}$ In 2016, specific legislation, based on the Council of Europe ResAPs (of either 2003 or 2008), existed in seven Member States and three European Free Trade Association countries. ${ }^{36}$ Therefore, studies prior to $2009 / 2010$ are unlikely to have any relevance anymore. Inks that do not adhere to the $\operatorname{Res} A P(2008) 1$ guidelines are expected to be withdrawn from the European market. Current inks on the European Union market are expected to have very low level of nickel impurities, which is an important safety net for patients with nickel allergy. It is also important to know when and where tattoos have been performed, as well as the origin of the inks, when analysing a tattooed skin sample.

Of note, a new Registration, Evaluation, Authorization and restriction of $\mathrm{CHemicals}(\mathrm{REACH})$ regulation on tattoo inks has been accepted in the European Union and will be in force from January 4, 2022. ${ }^{37}$

The exploration of tattoo allergy in a patient is also challenging. The chemistry of inks is complex and numerous components are possible culprits. No reliable standardized tests are available to identify the cause of these reactions in clinical practice. ${ }^{38}$ Missing information on the ingredients of the ink also has an impact on patch tests interpretation. The lack of studies on the importance of nickel release from tattoo needles should be mentioned. As the needle is forced 3000 times/minute through the epidermis and into the dermis, this area of research deserves more focus.

Lastly, limitations of our review are that we did not include possible ink studies performed by national authorities. Additional case reports with patch testing results positive to nickel may have been missed.

\section{7 | CONCLUSION}

The impact of nickel in tattoos remains largely unclear. Currently, the main difficulty lies in properly guiding individuals with nickel allergy who are willing to get tattooed. According to noncontrolled studies, nickel allergy seems to be more frequent in those with a tattoo reaction than in the general population. On the European market, professional manufacturers should respect the current European resolution and nickel should be now at the lowest achievable level. Regarding the implication of nickel in tattoo reactions, only large epidemiologic case-control studies would help to understand the role of nickel. Studies should not only include patients with tattoo reactions, but also tattooed controls. Explorations should not only include analysis of cutaneous biopsies from inflamed area, but also cutaneous biopsies from healthy tattoos and systematic patch testing should be performed.

\section{CONFLICTS OF INTEREST}

Nicolas Kluger is a honorary member of the Syndicat National des Artistes Tatoueurs (national syndicate of tattoo artists).

\section{DATA AVAILABILITY STATEMENT}

Data sharing not applicable - no new data generated

\section{ORCID}

Nicolas Kluger (D) https://orcid.org/0000-0002-5225-8316

\section{REFERENCES}

1. Kluger N, Seité S, Taieb C. The prevalence of tattooing and motivations in five major countries over the world. J Eur Acad Dermatol Venereol. 2019;33(12):e484-e486.

2. Serup J, Sepehri M, Hutton Carlsen K. Classification of tattoo complications in a hospital material of 493 adverse events. Dermatology. 2016;232(6):668-678.

3. Kluger N. Cutaneous complications related to tattoos: 31 cases from Finland. Dermatology. 2017;233(1):100-109.

4. Kluger N, Descamps V. Usefulness of a specialized « tattoo » consultation in a tertiary care hospital: a one-year experience. J Eur Acad Dermatol Venereol. 2019;33(4):e182-e183.

5. Kluger N. Tattoo skin reactions: management and treatment algorithm. Ann Dermatol Venereol. 2016;143(6-7):436-445.

6. van der Bent SAS, de Winter RW, Wolkerstorfer A, Rustemeyer T. Red tattoo reactions, a prospective cohort on clinical aspects. J Eur Acad Dermatol Venereol. 2019;33(10):e384-e386.

7. Hutton Carlsen K, Serup J. Patients with tattoo reactions have reduced quality of life and suffer from itch: dermatology life quality index and itch severity score measurements. Skin Res Technol. 2015; 21(1):101-107.

8. Dirks M. Making innovative tattoo ink products with improved safety: possible and impossible ingredients in practical usage. Curr Probl Dermatol. 2015;48:118-127.

9. Ahlström MG, Thyssen JP, Wennervaldt M, Menné T, Johansen JD. Nickel allergy and allergic contact dermatitis: a clinical review of immunology, epidemiology, exposure, and treatment. Contact Dermatitis. 2019;81(4):227-241.

10. Ahlström MG, Thyssen JP, Menné T, Johansen JD. Prevalence of nickel allergy in Europe following the EU nickel directive - a review. Contact Dermatitis. 2017;77(4):193-200.

11. Fors R, Persson M, Bergström E, Stenlund H, Stymne B, Stenberg B. Lifestyle and nickel allergy in a Swedish adolescent population: 
effects of piercing, tattooing and orthodontic appliances. Acta Derm Venereol. 2012;92(6):664-668.

12. Lagrelius M, Wahlgren CF, Matura M, Bergström A, Kull I, Lidén C. A population-based study of self-reported skin exposures and symptoms in relation to contact allergy in adolescents. Contact Dermatitis. 2017;77(4):242-249.

13. Taaffe A, Knight AG, Marks R. Lichenoid tattoo hypersensitivity. $\mathrm{Br}$ Med J. 1978;1(6113):616-618.

14. Clarke J, Black MM. Lichenoid tattoo reactions. Br J Dermatol. 1979; 100(4):451-454.

15. Timko AL, Miller CH, Johnson FB, Ross E. In vitro quantitative chemical analysis of tattoo pigments. Arch Dermatol. 2001;137(2):143-147.

16. Corazza M, Zampino MR, Montanari A, Pagnoni A, Virgili A. Lichenoid reaction from a permanent red tattoo: has nickel a possible aetiologic role? Contact Dermatitis. 2002;46(2):114-115.

17. Schmitz I, Müller KM. Elemental analysis of tattoo dyes-is there a potential risk from tattoo dyes? J Dtsch Dermatol Ges. 2004;2(5): 350-353.

18. Jäger $C$, Jappe U. Contact dermatitis to permanent make up: manifestation of a pre-existing nickel allergy. J Dtsch Dermatol Ges. 2005;3(7): 527-529.

19. Beute TC, Miller CH, Timko AL, Ross EV. In vitro spectral analysis of tattoo pigments. Dermatol Surg. 2008;34(4):508-515; discussion 515-516.

20. Forte G, Petrucci F, Cristaudo A, Bocca B. Market survey on toxic metals contained in tattoo inks. Sci Total Environ. 2009;407(23):59976002.

21. Cristaudo A, Forte G, Bocca B, et al. Permanent tattoos: evidence of pseudolymphoma in three patients and metal composition of the dyes. Eur J Dermatol. 2012;22(6):776-780.

22. Manso M, Pessanha S, Guerra M, et al. Assessment of toxic metals and hazardous substances in tattoo inks using Sy-XRF, AAS, and Raman spectroscopy. Biol Trace Elem Res. 2019;187(2):596-601.

23. Serup J, Hutton Carlsen K, Dommershausen N, et al. Identification of pigments related to allergic tattoo reactions in 104 human skin biopsies. Contact Dermatitis. 2020;82(2):73-82.

24. Sowden JM, Byrne JP, Smith AG, et al. Red tattoo reactions: X-ray microanalysis and patch-test studies. Br J Dermatol. 1991;124(6): 576-580.

25. Morales-Callaghan AM Jr, Aguilar-Bernier M Jr, Martínez-García G, Miranda-Romero A. Sarcoid granuloma on black tattoo. J Am Acad Dermatol. 2006;55(5 Suppl):S71-S73.

26. Schreiver I, Hesse B, Seim C, et al. Synchrotron-based $v$-XRF mapping and $\mu$-FTIR microscopy enable to look into the fate and effects of tattoo pigments in human skin. Sci Rep. 2017;7(1):11395.
27. van der Bent SAS, Berg T, Karst U, Sperling M, Rustemeyer T. Allergic reaction to a green tattoo with nickel as a possible allergen. Contact Dermatitis. 2019;81(1):64-66.

28. Serup J, Hutton Carlsen K. Patch test study of 90 patients with tattoo reactions: negative outcome of allergy patch test to baseline batteries and culprit inks suggests allergen(s) are generated in the skin through haptenization. Contact Dermatitis. 2014;71(5):255-263.

29. Warshaw EM, Schlarbaum JP, Taylor JS, et al. Allergic reactions to tattoos: retrospective analysis of north American contact dermatitis group data, 2001-2016. J Am Acad Dermatol. 2020;82(2):e61-e62.

30. Gaudron S, Ferrier-Le Bouëdec MC, Franck F, D'Incan M. Azo pigments and quinacridones induce delayed hypersensitivity in red tattoos. Contact Dermatitis. 2015;72(2):97-105.

31. Schreiver I, Hesse B, Seim C, et al. Distribution of nickel and chromium containing particles from tattoo needle wear in humans and its possible impact on allergic reactions. Part Fibre Toxicol. 2019;16(1):33.

32. Prior G. Tattoo Inks: Analysis. Berlin: Pigments, Legislastion. epubli $\mathrm{GmbH} ; 2014$.

33. Kluger N. Epidemiology of tattoos in industrialized countries. Curr Probl Dermatol. 2015;48:6-20.

34. Thyssen JP, Johansen JD, Menné T, Nielsen NH, Linneberg A. Effect of tobacco smoking and alcohol consumption on the prevalence of nickel sensitization and contact sensitization. Acta Derm Venereol. 2010;90(1):27-33.

35. Resolution $\operatorname{Res} A P(2008) 1$ on requirements and criteria for the safety of tattoos and permanent make-up (superseding Resolution ResAP (2003)2 on tattoos and permanent make-up). 2008. https://rm.coe. int/16805d3dc4. Accessed January 8, 2021.

36. Piccinini P, Pakalin S, Contor L, Bianchi I, Senaldi C. Safety of tattoos and permanent make-up: final report. JRC Science for policy report. 2016. https://ec.europa.eu/jrc/en/publication/eur-scientific-andtechnical-research-reports/safety-tattoos-and-permanent-makefinal-report. Accessed January 8, 2021.

37. ECHA. Tattoo inks and permanent make-up. 2021. . https://echa. europa.eu/hot-topics/tattoo-inks. Accessed April 9, 2021.

38. De Cuyper C. Tattoo allergy. Can we identify the allergen? Presse Med. 2020;49(4):104047.

How to cite this article: Kluger N. Nickel and tattoos: Where are we? Contact Dermatitis. 2021;1-5. https://doi.org/10. 1111/cod.13869 